\title{
Direct Spectroscopy for Probing the Critical Role of Partial Covalency in Oxygen Reduction Reaction for Cobalt-Manganese Spinel Oxides
}

\author{
Xinghui Long 1,2,3® Pengfei Yu ${ }^{1,2}$, Nian Zhang ${ }^{1,2}$, Chun Li ${ }^{4}$, Xuefei Feng ${ }^{5}$, Guoxi Ren ${ }^{1,2,3}$, \\ Shun Zheng $1,2,3$, Jiamin Fu ${ }^{1,2,6}$, Fangyi Cheng ${ }^{4}$ and Xiaosong Liu ${ }^{1,2,6, *}$ \\ 1 State Key Laboratory of Functional Materials for Informatics, Shanghai Institute of Microsystem and \\ Information Technology, Chinese Academy of Sciences, Shanghai 200050, China; \\ xhlong@mail.sim.ac.cn (X.L.); ypfaq@mail.sim.ac.cn (P.Y.); zhangn@mail.sim.ac.cn (N.Z.); \\ gxren@mail.sim.ac.cn (G.R.); shunzheng@mail.sim.ac.cn (S.Z.); fujm@shanghaitech.edu.cn (J.F.) \\ 2 CAS Center for Excellence in Superconducting Electronics (CENSE), Chinese Academy of Sciences, \\ Shanghai 200050, China \\ 3 University of Chinese Academy of Sciences, Beijing 100049, China \\ 4 Key Laboratory of Advanced Energy Materials Chemistry (Ministry of Education) and State Key Laboratory \\ of Elemento-Organic Chemistry, College of Chemistry, Nankai University, Tianjin 300071, China; \\ kemistlic@foxmail.com (C.L.); fycheng@nankai.edu.cn (F.C.) \\ 5 Advanced Light Source, Lawrence Berkeley National Laboratory, Berkeley, CA 94720, USA; \\ xuefeifeng2013@gmail.com \\ 6 School of Physical Science and Technology, Shanghai Tech University, Shanghai 200031, China \\ * Correspondence: xliu3@mail.sim.ac.cn; Tel.: +86-021-6251-1070
}

Received: 25 February 2019; Accepted: 1 April 2019; Published: 9 April 2019

check for updates

\begin{abstract}
Nanocrystalline multivalent metal spinels are considered as attractive non-precious oxygen electrocatalysts. Identifying their active sites and understanding their reaction mechanisms are essential to explore novel transition metal (TM) oxides catalysts and further promote their catalytic efficiency. Here we report a systematic investigation, by means of soft X-ray absorption spectroscopy (sXAS), on cubic and tetragonal $\mathrm{Co}_{\mathrm{x}} \mathrm{Mn}_{3-\mathrm{x}} \mathrm{O}_{4}(\mathrm{x}=1,1.5,2)$ spinel oxides as a family of highly active catalysts for the oxygen reduction reaction (ORR). We demonstrate that the ORR activity for oxide catalysts primarily correlates to the partial covalency of between $\mathrm{O} 2 \mathrm{p}$ orbital with $\mathrm{Mn}^{4+}$ $3 \mathrm{~d} \mathrm{t}_{2 \mathrm{~g}}$-down/ $\mathrm{e}_{\mathrm{g}}$-up, $\mathrm{Mn}^{3+} 3 \mathrm{~d} \mathrm{e}_{\mathrm{g}}$-up and $\mathrm{Co}^{3+} 3 \mathrm{~d} \mathrm{e}_{\mathrm{g}}$-up orbitals in octahedron, which is directly revealed by the $\mathrm{O}$ K-edge sXAS. Our findings propose the critical influences of the partial covalency between oxygen $2 p$ band and specific metal $3 d$ band on the competition between intermediates displacement of the ORR, and thus highlight the importance of electronic structure in controlling oxide catalytic activity.
\end{abstract}

Keywords: oxygen reduction reaction; spinel oxides; soft X-ray absorption spectroscopy; partial covalency; catalytic activity

\section{Introduction}

The oxygen reduction reaction (ORR) and/or oxygen evolution reaction (OER) on an oxygen-based electrode are essential for a wide range of electrochemical energy conversion and storage technologies, such as direct solar cell [1], electrolytic water splitting [2], rechargeable metal-air batteries [3], and regenerative fuel cells [4]. However, the intrinsic slow kinetics of ORR/OER is the obstacle for their application. It is a great challenge to seek for highly active catalysts to improve the efficiency of ORR and OER. To date, the best known catalysts for oxygen electrocatalysis are 
Pt-alloy catalysts for the ORR [5] and iridium-oxide- or ruthenium-oxide-based catalysts for the OER [6]. Unfortunately, the scarce crustal abundance of the noble metals limits their commercial viability. Transition metal (TM) oxides and carbon materials with excellent electrocatalysts and high stability [7-9], owing many advantages such as high abundance, low-cost, easy prepared, and environmental friendliness, are considered as an alternative to noble metals. In particularly, spinel oxides have been widely used as catalyst for ORR and/or OER [10-16]. In pursuit of further enhanced oxygen electrocatalytic activity, it is necessary to understand the catalytic mechanism of TM oxides and to identify the activity site, which has attracted extensive research efforts.

For instance, Rios et al. found that the surface $\mathrm{Co}^{3+}$ in $\mathrm{Mn}_{x} \mathrm{Co}_{3-\mathrm{x}} \mathrm{O}_{4}(x>0)$ was the active site, which made $\mathrm{Co}_{3} \mathrm{O}_{4}$ the most active for OER [17]. On the contrary, Restovic et al. pointed out that the electrocatalytic activity in $\mathrm{Mn}_{\mathrm{x}} \mathrm{Co}_{3-\mathrm{x}} \mathrm{O}_{4}$ of the ORR was correlated to the Mn content, and more precisely to the amount of $\mathrm{Mn}^{4+} / \mathrm{Mn}^{3+}$ pairs [18]. These results suggested that two metals in dual-metal spinel system and their redox pairs play different roles in influencing the catalytic performances for ORR or OER. Based on a systematic study of 3d TM perovskite oxides, Shao-Horn Yang et al. discovered a volcano shape relationship between the $\mathrm{e}_{\mathrm{g}}$-filling descriptor, depicting filling degree of the surface active ions $e_{g}$ orbital, and the catalytic activity of ORR/OER $[19,20]$. Almost at the same time, Zhichuan J. Xu et al. speculated that the e occupancy of the active cation in the octahedral site is the activity descriptor for the ORR/OER of spinels [21,22]. They also elucidated, based on an investigation of the composition dependence of ORR in $\mathrm{ZnCo}_{x} \mathrm{Mn}_{2-\mathrm{x}} \mathrm{O}_{4}(\mathrm{x}=0.0-2.0)$ spinel, that the modulated $\mathrm{e}_{\mathrm{g}}$ occupancy of active Mn cations, as a consequence of the superexchange effect between edge sharing $\left[\mathrm{CoO}_{6}\right]$ and $\left[\mathrm{MnO}_{6}\right]$ octahedra, correlated to the ORR activity [22]. However, David N. Mueller et al. revealed that the oxygen anions near the surface rather than the TM cations were a significant redox partner to molecular oxygen because of the strong covalency between oxygen $2 \mathrm{p}$ orbital and TM $3 \mathrm{~d}$ orbital in oxygen-deficient perovskite oxides [23]. In addition, the covalency between metal-d and oxygen-p had been reported to play a critical role in increasing the activities of oxygen electrocatalysis [19,24]. Obviously, although the spinel oxides have been extensively studied, it is still under debate about their catalytic mechanism of ORR or OER activity, especially for dual-metal spinel oxides.

To tackle this long-standing and important fundamental problem, we herein report a systematic and detailed study of a series of nanocrystalline dual-metal spinals $\mathrm{Co}_{\mathrm{x}} \mathrm{Mn}_{3-\mathrm{x}} \mathrm{O}_{4}$ through a detailed study with soft X-ray absorption spectroscopy (sXAS). The aforementioned facile synthesis methodology [25] facilitates selective formation of cubic or tetragonal phases and various compositions of $\mathrm{Co}_{\mathrm{x}} \mathrm{Mn}_{3-\mathrm{x}} \mathrm{O}_{4}(\mathrm{x}=1,1.5,2)$ nanoparticles, which are believed as two main factors affecting their ORR catalytic activities. The subtle variation in TM L-edge spectra for both cubic and tetrahedral samples indicates very little valance change of TM with the variation of the component proportion. Surprisingly, the notable differences are observed, associated with the substitution of Co by Mn, from O K-edge absorption spectra, in particular the pre-edge structures that arise from the covalent mixture of metal-3d and oxygen-2p electronic states. These covalent characteristics is analyzed in depth through the deconvolution of pre-edge features and comparison to a series of reference samples to identify their origins. Our results suggest that the partial covalency of $\mathrm{O} 2 \mathrm{p}$ orbital with $\mathrm{Mn}^{4+} 3 \mathrm{~d} \mathrm{t}_{2 \mathrm{~g}}$-down/ $\mathrm{e}_{\mathrm{g}}$-up, $\mathrm{Mn}^{3+} 3 \mathrm{~d}$ e $\mathrm{g}$-up and $\mathrm{Co}^{3+} 3 \mathrm{~d} \mathrm{e}_{\mathrm{g}}$-up orbitals have stronger correlation than other orbitals to the ORR catalytic activities. These findings may provide a new experimental evidence from the point of view of electronic structure to unveil the catalytic mechanism of dual-metal spinels.

\section{Experimental Method}

\subsection{Synthesis of $\mathrm{Co}_{x} \mathrm{Mn}_{3-x} \mathrm{O}_{4}$ Oxides and Electrochemical Characterization}

The $\mathrm{Co}_{\mathrm{x}} \mathrm{Mn}_{3-\mathrm{x}} \mathrm{O}_{4}$ oxides were obtained by a solution synthesis method. In a typical synthesis of $\mathrm{Co}_{\mathrm{x}} \mathrm{Mn}_{3-\mathrm{x}} \mathrm{O}_{4}$ spinel oxide, $\mathrm{Co}\left(\mathrm{NO}_{3}\right)_{2}$ and $\mathrm{Mn}\left(\mathrm{NO}_{3}\right)_{2}$ (Sigma Aldrich, St. Louis, MO, USA) were used as precursor of cobalt and manganese, respectively. The specific steps can be summarized as stirring the 
solution containing aqueous ammonia (Sigma Aldrich, St. Louis, MO, USA), $\mathrm{Co}\left(\mathrm{NO}_{3}\right)_{2}$ and $\mathrm{Mn}\left(\mathrm{NO}_{3}\right)_{2}$ solution, then evaporating by heating to obtain the final spinel oxide. Different ratios $x$ and phase structure were obtained by controlling the molar ratio of cobalt and manganese precursor and the order of adding ammonia water, $\mathrm{Co}\left(\mathrm{NO}_{3}\right)_{2}$ and $\mathrm{Mn}\left(\mathrm{NO}_{3}\right)_{2}$ solution, respectively.

To test the electrochemical performance, a three electrodes electrochemical cell were used, which contains a calomel reference electrode, a Pt counter electrode and a working electrode, respectively. Catalyst ink, containing spinels oxide, carbon powder, water, isopropyl alcohol and neutralized Nafion solution (Sigma Aldrich, St. Louis, MO, USA), was pipetted on the glassy carbon electrode to form the working electrode. The PARSTAT 263A workstation (AMETEK, Berwyn, PA, USA) accompanied with a model 636 system (AMETEK, Berwyn, PA, USA) was used to record the voltammetry data with a potential scan rate of $5 \mathrm{mV} \mathrm{s}^{-1}$. Measurements were carried out in $0.1 \mathrm{M}$ aqueous $\mathrm{KOH}$ saturated with either purified $\mathrm{Ar}$ or $\mathrm{O}_{2}$ at room temperature. All potentials were calibrated with reference to standard reversible hydrogen electrode. The detailed experimental methods can refer to reference [26].

\subsection{Soft X-ray Absorption Spectroscopy (sXAS)}

sXAS were performed at beamline 20A1 of National Synchrotron Radiation Research Center (NSRRC) in Hsinchu, Taiwan. The storage ring was operated with energy of $1.5 \mathrm{GeV}$ and a current of $300 \mathrm{~mA}$. The beamline was equipped with a 6-m high-energy spherical grating monochromator (6m-HSGM) to supply a photon beam with resolving power up to 8000 [27]. The spectra were collected in total electron yield (TEY) mode in an under ultrahigh-vacuum (UHV) chamber with a base pressure about $5 \times 10^{-10}$ Torr, corresponding to probe depth of about $10 \mathrm{~nm}$. All the spectra have been normalized to the photocurrent from the upstream clean gold mesh to eliminate the fluctuation of the beam flux. The photon energy was calibrated with the spectra of reference samples ( $\mathrm{MnO}$ for $\mathrm{Mn}$ L-edge, $\mathrm{CoO}$ for $\mathrm{Co} \mathrm{L}$-edge and $\mathrm{SrTiO}_{3}$ for O K-edge) measured simultaneously.

\section{Results and Discussion}

Cubic and tetragonal spinel $\mathrm{Co}_{\mathrm{x}} \mathrm{Mn}_{3-\mathrm{x}} \mathrm{O}_{4}(\mathrm{x}=1,1.5,2)$ samples (labeled as $\mathrm{C}-\mathrm{Co}_{1}, \mathrm{C}-\mathrm{Co}_{1.5}, \mathrm{C}-\mathrm{Co}_{2}$, $\mathrm{T}-\mathrm{Co}_{1}, \mathrm{~T}-\mathrm{Co}_{1.5}$, and $\mathrm{T}-\mathrm{Co}_{2}$, respectively) are obtained by solution synthesis method and their crystal structure are shown in Figure 1a,c. Spinel oxides have $A\left[B_{2}\right] X_{4}$ molecular formula, in which A stands for cations occupied eighth of the tetrahedral sites, B stands for cations occupied half of the octahedral sites, and $\mathrm{X}$ represents oxygen anions with a close-packed structure. The structure, morphology and ORR performance of $\mathrm{Co}_{x} \mathrm{Mn}_{3-\mathrm{x}} \mathrm{O}_{4}(\mathrm{x}=1,1.5,2)$ can be found in the previous report [26]. The different ORR performance can be viewed from the half-wave potential $E_{1 / 2}$ versus reversible hydrogen electrode (RHE) acquired from the polarization profiles, as shown in Figure 1b,d. For both cubic and tetrahedral phases, the activities decrease with the increase of $\mathrm{Co} / \mathrm{Mn}$ ratio, i.e., $\mathrm{CoMn}_{2}>\mathrm{Co}_{1.5} \mathrm{Mn}_{1.5}>$ $\mathrm{Co}_{2} \mathrm{Mn}$. The results indicate that lower $\mathrm{Co} / \mathrm{Mn}$ ratio are more favorable to intrinsic catalytic activity. 
(a)

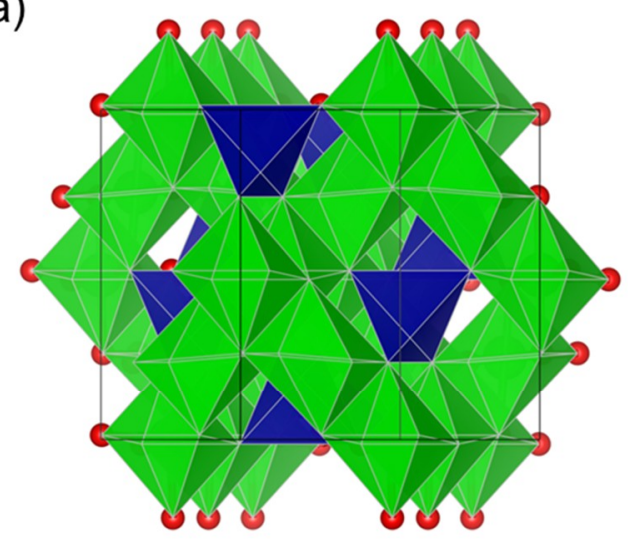

(c)

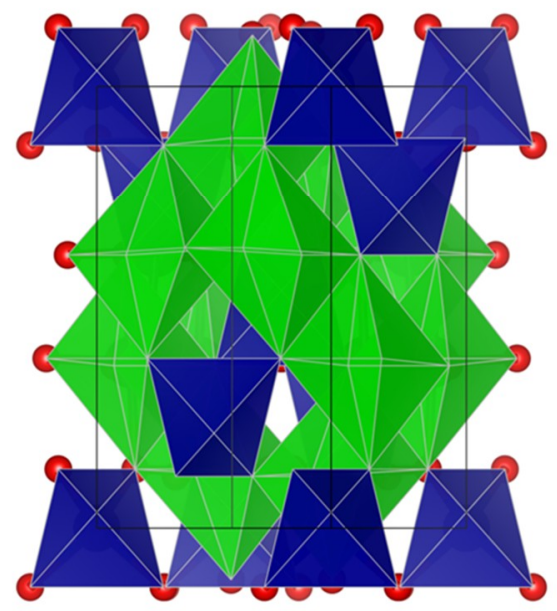

(b)

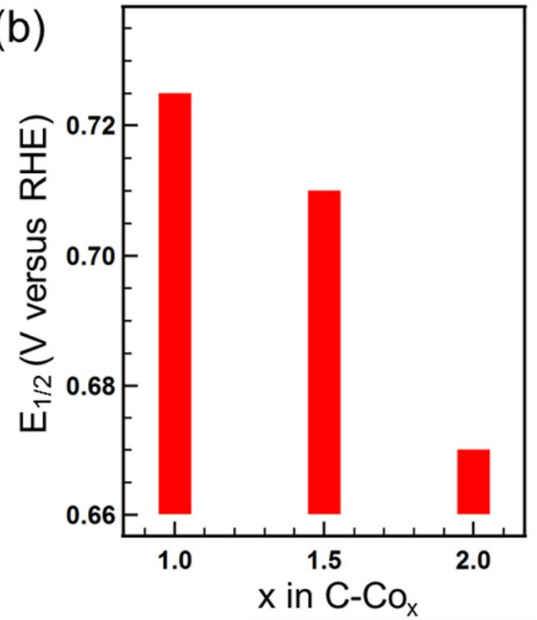

(d)

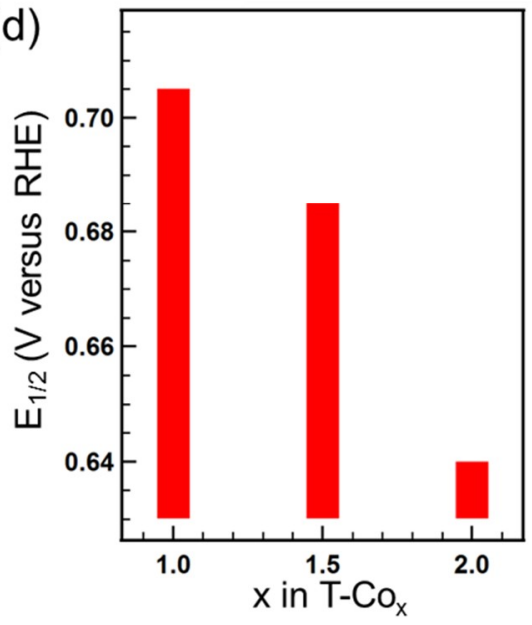

Figure 1. (a,c) Structure diagram of cubic and tetragonal spinel oxides, respectively. The red ball, blue polyhedron, and green polyhedron represent the oxygen anion, tetrahedron, and octahedron, respectively. (b,d) The half-wave potential $\mathrm{E}_{1 / 2}$ versus the Co content $\mathrm{x}$ in the cubic and tetragonal series, respectively. ( $5 \mathrm{mV} \mathrm{s}^{-1}$ scan rate).

To reveal the effect of the Co/Mn ratio on the electronic structure and get a deep insight into its relationship with the catalytic performance, TM L-edge sXAS spectra are firstly studied. The sXAS spectra of $\mathrm{Co}$ and $\mathrm{Mn}$ L-edge of cubic and tetragonal $\mathrm{Co}_{\mathrm{x}} \mathrm{Mn}_{3-\mathrm{x}} \mathrm{O}_{4}(\mathrm{x}=1,1.5,2)$ under UHV condition are shown in Figure 2a,b, respectively. It can be seen that both the Co and Mn L-edge spectra split into two separate sets of peaks named as $\mathrm{L}_{3}$ and $\mathrm{L}_{2}$-edge as a result of the $2 \mathrm{p}$ spin-orbital coupling interaction. We herein focus on the evolution of $\mathrm{L}_{3}$-edge because of the stronger intensities and refined features compared to $\mathrm{L}_{2}$-edge. Based on the reference samples with different valence states and published results [28-31], the peak $\mathrm{A}(\sim 779 \mathrm{eV})$ and peak $\mathrm{B}(\sim 780.6 \mathrm{eV})$ are assigned to the $\mathrm{Co}^{2+}$ and $\mathrm{Co}^{3+}$ states, respectively. The overall lineshape indicates that the $\mathrm{Co}$ of $\mathrm{Co}_{x} \mathrm{Mn}_{3-\mathrm{x}} \mathrm{O}_{4}$ primarily exist in a mixed $2+/ 3+$ oxidation state. The subtle spectral variations with different $\mathrm{Co} / \mathrm{Mn}$ ratios imply little valance changes of $\mathrm{Co}$ for both the cubic and tetragonal phases. Moreover, all spectra of $\mathrm{Co}_{\mathrm{x}} \mathrm{Mn}_{3-\mathrm{x}} \mathrm{O}_{4}$ are very similar to the spectrum of spinel $\mathrm{Co}_{3} \mathrm{O}_{4}$, suggesting that the $\mathrm{Co}^{2+}$ and $\mathrm{Co}^{3+}$ occupy the tetrahedral and octahedral sites, respectively [28,32-34]. The Mn L-edge sXAS spectra show similar phenomena. Following the same analysis, we are able to identify that the oxidations of Mn in $\mathrm{Co}_{x} \mathrm{Mn}_{3-x} \mathrm{O}_{4}$ primarily exist in a mixed 3+/4+ state in comparison with previous studies [29,35-37].

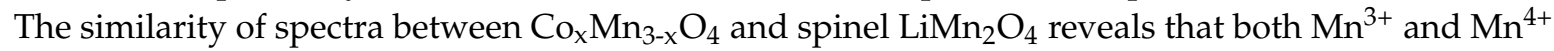
occupy the octahedral sites. More distinct variation with the alteration of $\mathrm{x}$ in $\mathrm{Co}_{\mathrm{x}} \mathrm{Mn}_{3-\mathrm{x}} \mathrm{O}_{4}$ are observed in the Mn L-edge spectra than the Co L-edge. As the valance state of Mn is higher than Co, the valance 
changes state that $\mathrm{TM}$ or $\mathrm{O}$ vacancies are created during the synthetic process, which is consistent with previous report [26]. Besides, it has been well established that the high spin states correspond to large branching ratio $\mathrm{I}\left(\mathrm{L}_{3}\right) /\left[\mathrm{I}\left(\mathrm{L}_{3}\right)+\mathrm{I}\left(\mathrm{L}_{2}\right)\right][38,39]$. The small branching ratio at Co L-edge and large in Mn L-edge clear that Co stays at low-spin state [31] and Mn at high-spin state [40] in all samples, respectively.
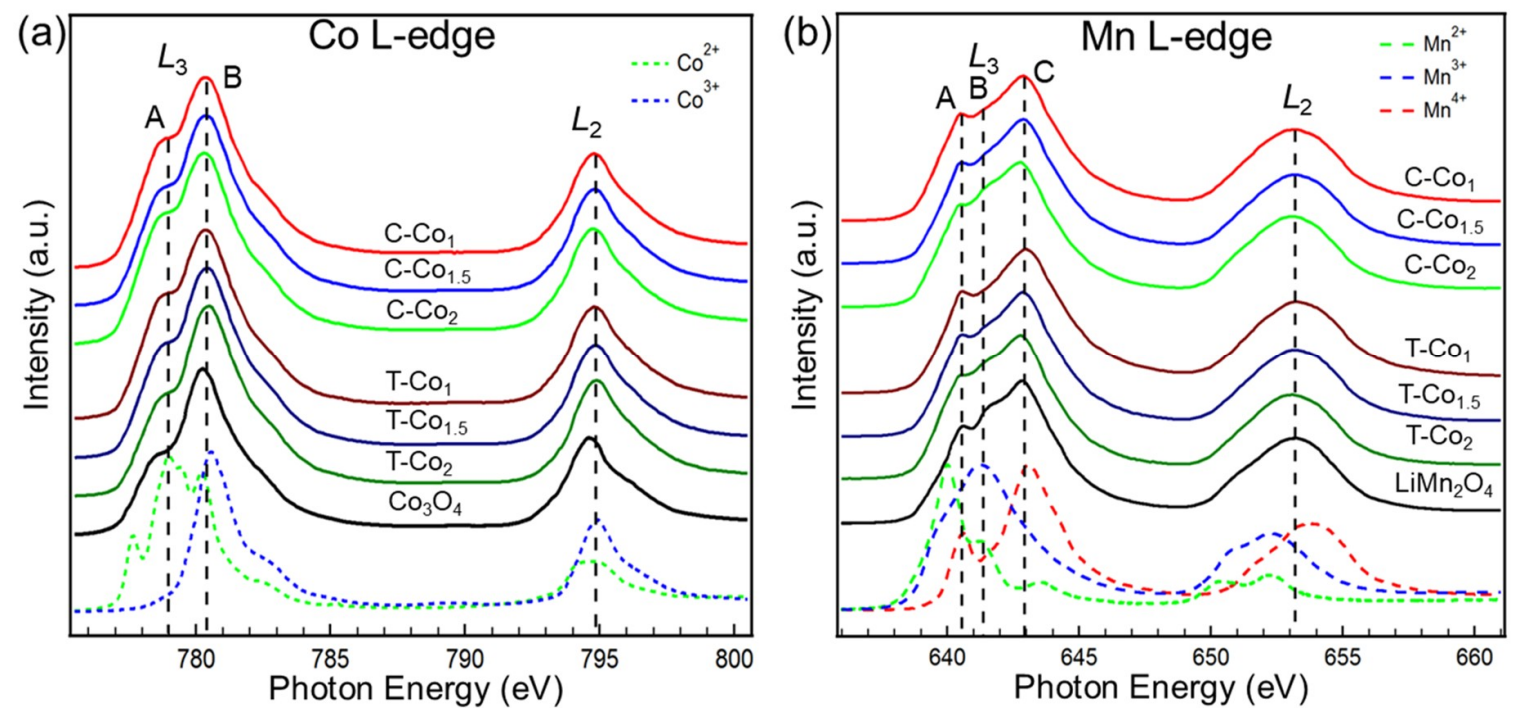

Figure 2. (a) Co L-edge soft X-ray absorption spectroscopy (sXAS) spectra of the spinel oxides with $\mathrm{Co}^{2+}(\mathrm{CoO}), \mathrm{Co}^{3+}\left(\mathrm{LiCoO}_{2}\right)$ and $\mathrm{Co}_{3} \mathrm{O}_{4}$. (b) Mn L-edge sXAS spectra of spinel oxides with $\mathrm{Mn}^{2+}(\mathrm{MnO})$, $\mathrm{Mn}^{3+}\left(\mathrm{Mn}_{2} \mathrm{O}_{3}\right), \mathrm{Mn}^{4+}\left(\mathrm{Li}_{2} \mathrm{MnO}_{3}\right)$, and $\mathrm{LiMn}_{2} \mathrm{O}_{4}$.

Since very little changes from TM L-edge are observed with the alteration of $\mathrm{Co} / \mathrm{Mn}$ ratio, O K-edge is examined to further track the possible evolution of electronic structure. The O K-edge sXAS spectra of the spinel oxides in Figure 3a can be divided into two regions. The first region $(529 \sim 535 \mathrm{eV})$ shown in the shade, so-called pre-edge, is primarily associated with the $\mathrm{O}$ 1s to unoccupied O 2p-TM $3 \mathrm{~d}$ hybridized states. The second region (above $535 \mathrm{eV}$ ) has been attributed to the excitations of $\mathrm{O} 1 \mathrm{~s}$ to O 2p-TM 4sp states [23,24,29,41]. Different from the TM L-edge, a significant change is observed in the $\mathrm{O} 2 \mathrm{p}-\mathrm{TM} 3 \mathrm{~d}$ region of $\mathrm{O} \mathrm{K}$-edge. The energy position of the peak A shifts to high energy as the cobalt content $x$ increases, and the intensity ratio between peak $A$ and $B$ also changes for both cubic and tetragonal phases. This suggests that the $\mathrm{M} 3 \mathrm{~d}-\mathrm{O} 2 \mathrm{p}$ covalency may be regulated by changing the ratio $\mathrm{x}$ in $\mathrm{Co}_{\mathrm{x}} \mathrm{Mn}_{3-\mathrm{x}} \mathrm{O}_{4}$ oxides. In order to further testify if there exists an ORR activity-determining factor related to M 3d-O 2p covalency, we investigate how the ORR activity and M 3d-O 2p covalency changes as a function of $\mathrm{x}$ in $\mathrm{Co}_{\mathrm{x}} \mathrm{Mn}_{3-\mathrm{x}} \mathrm{O}_{4}$. The normalized absorbance percentage, which is estimated by the percentage of shaded area with subtracting a linear background relative to the entire area of the curve showed in Figure 3a, is used to quantify the strength of M 3d-O 2p covalency. To identify the effect of the covalency of $\mathrm{M} 3 \mathrm{~d}-\mathrm{O} 2 \mathrm{p}$ on the ORR activity, we plot the normalized absorbance percentage versus the half-wave potential $\mathrm{E}_{1 / 2}$ in Figure $3 \mathrm{~b}$. The $\mathrm{M} 3 \mathrm{~d}-\mathrm{O} 2 \mathrm{p}$ covalency exhibits a consistent variation trend with the ORR performance in the tetragonal phase, which demonstrates that increasing the M 3d-O 2p covalency positively affects ORR activity. On the contrary, this correlation cannot be observed in the cubic phase. It evidenced that the strength of the M 3d-O 2p covalency is not a common descriptor of the ORR performance for both the cubic and tetragonal phases. More complicated underlying mechanism may play more crucial role to determine their catalytic activity. 

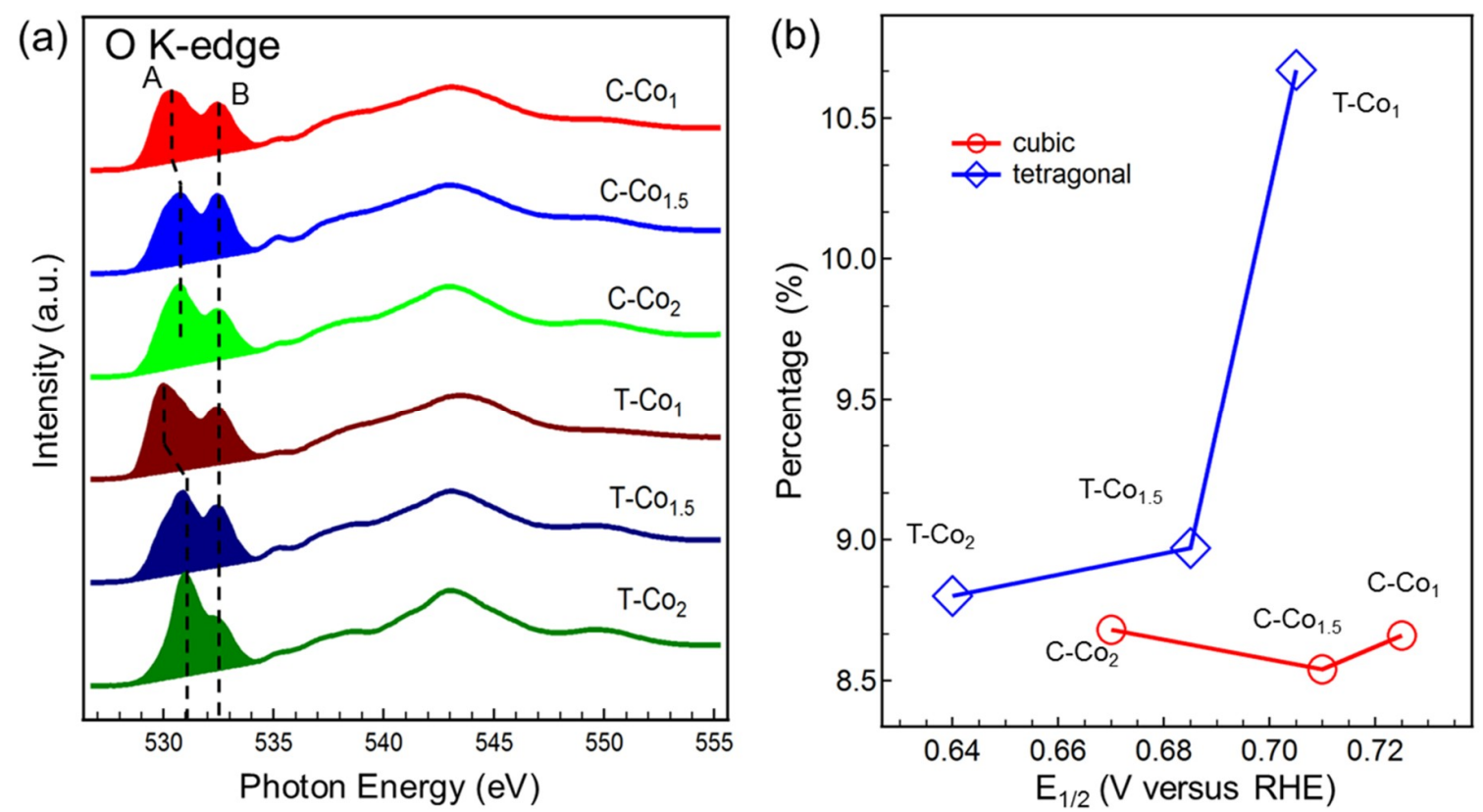

Figure 3. The role of $\mathrm{M} 3 \mathrm{~d}-\mathrm{O} 2 \mathrm{p}$ covalency on the oxygen reduction reaction (ORR) activity of $\mathrm{Co}_{\mathrm{x}} \mathrm{Mn}_{3-\mathrm{x}} \mathrm{O}_{4}$ spinel oxides. (a) O K-edge sXAS spectra of cubic and tetragonal $\mathrm{Co}_{\mathrm{x}} \mathrm{Mn}_{3-\mathrm{x}} \mathrm{O}_{4}(\mathrm{x}=1$, $1.5,2)$. Reproduced with permission from [26]. Copyright Nature Publishing Group, 2015. (b) the normalized absorbance percentage (absorbance percentage from the shaded section in A) versus the half-wave potential $E_{1 / 2}$.

The complexity of dual-metal spinels and the abundant features in the pre-edge of O K-edge sXAS spectra inspire us to perform a more in-depth analysis. First of all, we compare a series of reference samples $\left(\mathrm{Co}_{3} \mathrm{O}_{4}, \mathrm{LiCoO}_{2}, \mathrm{Li}_{2} \mathrm{MnO}_{3}, \mathrm{Mn}_{2} \mathrm{O}_{3}\right)$ along with our sample $\mathrm{C}-\mathrm{Co}_{1}$, as shown in the Figure $4 \mathrm{a}$, to figure out the contributions of the $\mathrm{Co}^{2+}$ at tetrahedral site as well as the $\mathrm{Co}^{3+}, \mathrm{Mn}^{3+}$, and $\mathrm{Mn}^{4+}$ at octahedral sites to $\mathrm{O}$ K-edge spectra. The pre-edge features of $\mathrm{Co}_{3} \mathrm{O}_{4}$ are very similar to the $\mathrm{LiCoO}_{2}$, except for an additional weak shoulder at $\sim 532.6 \mathrm{eV}$ corresponding to the $\mathrm{Co}^{2+}$ at tetrahedral site. This declares that the contribution of $\mathrm{Co}^{2+}$ in the tetrahedron to the O-K pre-edge is negligible in spinel oxides. For Mn-containing oxides, two well-resolved peaks are observed in $\mathrm{Li}_{2} \mathrm{MnO}_{3}$ and $\mathrm{Mn}_{2} \mathrm{O}_{3}$ and their lineshapes are very different. The high-energy peak of $\mathrm{Mn}_{2} \mathrm{O}_{3}$ is broadening and probably the superposition of two peaks [36]. A glancing comparison between the $\mathrm{C}-\mathrm{Co}_{1}$ and these reference samples illustrates, as shown by the dotted line in the Figure $4 \mathrm{a}$, that the pre-edge of $\mathrm{Co}_{\mathrm{x}} \mathrm{Mn}_{3-\mathrm{x}} \mathrm{O}_{4}$ contains all specific features, which can be considered as the spectral fingerprint of $\mathrm{Co}^{2+}$ at tetrahedral site as well as the $\mathrm{Co}^{3+}, \mathrm{Mn}^{3+}$, and $\mathrm{Mn}^{4+}$ at octahedral sites. Furthermore, we perform a quantitative analysis by spectral fitting method, as shown in Figure 4b (and Figure S1 in Supplementary Materials) [42,43]. In detail, symmetrically constrained Gaussian features and an arctangent function background are employed to do curve fitting. The full width at half maximum (FWHM) and energy position of the Gaussian functions and the arctangent background for the spectra peak deconvolution are listed in Tables $\mathrm{S} 1$ and $\mathrm{S} 2$ in supplementary materials. The most important information gained from this analysis is that the $\mathrm{O}-\mathrm{K}$ pre-edge of $\mathrm{Co}_{\mathrm{x}} \mathrm{Mn}_{3-\mathrm{x}} \mathrm{O}_{4}$ can be deconvoluted by four well-resolved intense Gaussian features labeled as P1-P4, representing four partial covalency of different $\mathrm{Co}-\mathrm{O}$ and $\mathrm{Mn}-\mathrm{O}$. In addition, their intensities can be determined by the area of the corresponding curve-fitting functions. 

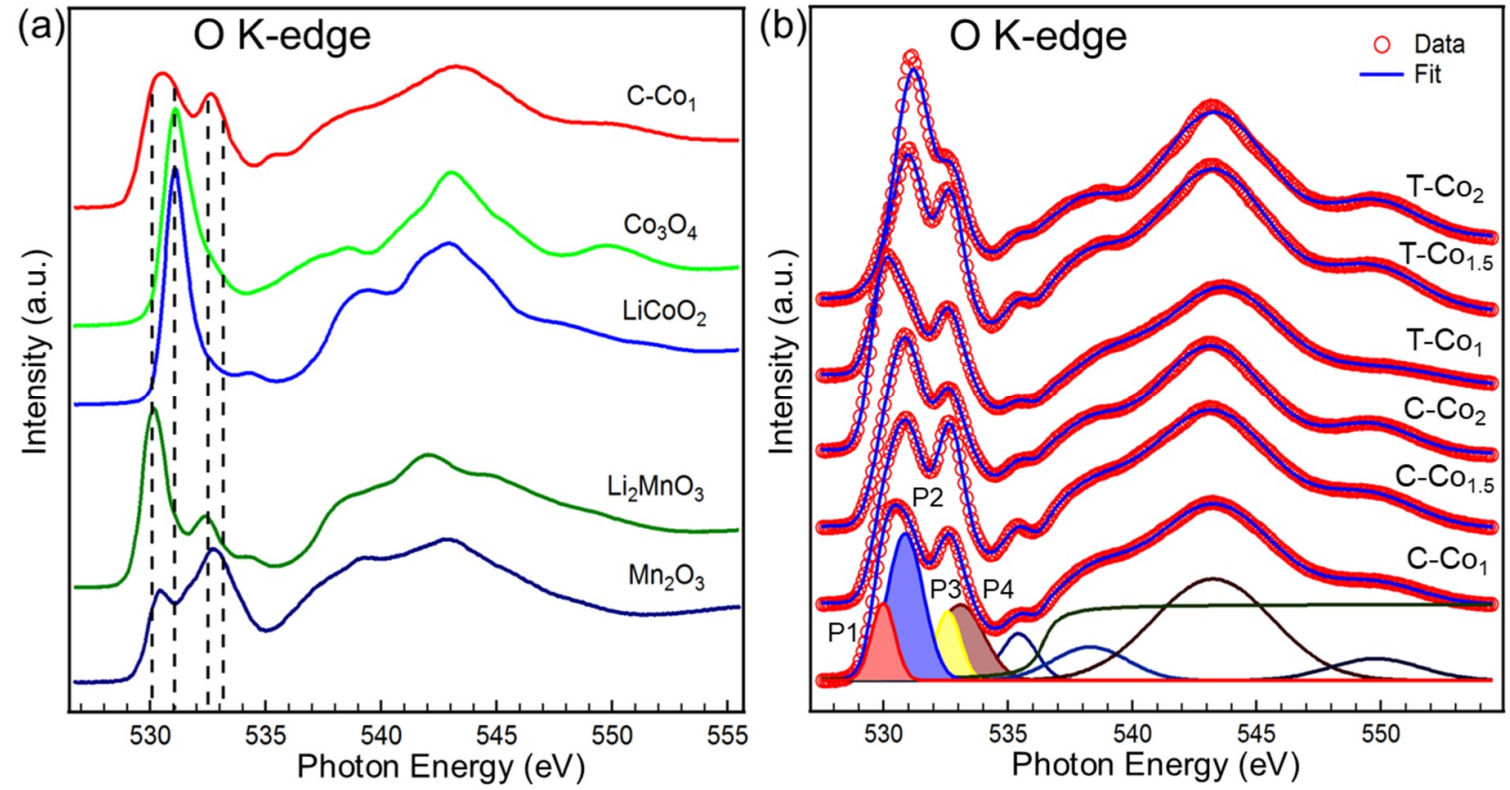

Figure 4. (a) $\mathrm{O}$ K-edge sXAS spectra of $\mathrm{Mn}_{2} \mathrm{O}_{3}, \mathrm{Li}_{2} \mathrm{MnO}_{3}, \mathrm{LiCoO}_{2}, \mathrm{Co}_{3} \mathrm{O}_{4}$, and $\mathrm{C}-\mathrm{Co}_{1}$. (b) O K-edge XAS signals of the spinel oxides; the peak decomposition has also been indicated in the figure. The experimental data are shown with the open red circles and the fitted results are shown with the solid blue line. Shaded Gaussian peaks (P1, P2, P3, and P4) represent the M 3d-O 2p covalency.

To further visualize the correlations between the P1-P4 features and the specific $3 \mathrm{~d}$ orbitals of $\mathrm{Mn}^{3+}, \mathrm{Mn}^{4+}$, and $\mathrm{Co}^{3+}$ in octahedral sites, the quantitative molecular orbital diagram is generated in Figure 5 by considering crystal field and spin states. For high-spin $\mathrm{Mn}^{4+}\left(3 \mathrm{~d}^{3}, \mathrm{t}_{2 \mathrm{~g}}{ }^{3}\right)$ in $\mathrm{Li}_{2} \mathrm{MnO}_{3}$, only two peaks were observed from the transitions to $t_{2 \mathrm{~g}}$-down/ $\mathrm{e}_{\mathrm{g}}$-up $(\sim 530.2 \mathrm{eV})$ and $\mathrm{e}_{\mathrm{g}}$-down $(\sim 532.4 \mathrm{eV})$ states. For high-spin $\mathrm{Mn}^{3+}\left(3 \mathrm{~d}^{4}, \mathrm{t}_{2 \mathrm{~g}}{ }^{3} \mathrm{e}_{\mathrm{g}}{ }^{1}\right)$ in $\mathrm{Mn}_{2} \mathrm{O}_{3}$, triple-peak structure was observed from the transitions to e $\mathrm{g}$-up $(\sim 530.4 \mathrm{eV}), \mathrm{t}_{2 \mathrm{~g}}$-down $(\sim 531.4 \mathrm{eV})$, and $\mathrm{e}_{\mathrm{g}}$-down $(533.2 \mathrm{eV})$ states $[36,40]$. For low-spin $\mathrm{Co}^{3+}\left(3 \mathrm{~d}^{6}, \mathrm{t}_{2 \mathrm{~g}}{ }^{6}\right)$ in $\mathrm{LiCoO}_{2}$, two-peak structure was observed from the transitions to $\mathrm{e}_{\mathrm{g}}$-up $(\sim 531.2 \mathrm{eV})$ and $\mathrm{e}_{\mathrm{g}}$-down $(532.6 \mathrm{eV})$ states. Considering the energy position of the Gaussian peaks and the specific $3 \mathrm{~d}$ orbital of the references in Figure 5, we assign the partial covalency of specific orbital to the four Gaussian peaks of pre-edge portion. For P2 feature, two sources of partial covalency are $\mathrm{Co}^{3+}$ $3 \mathrm{~d} \mathrm{e}_{\mathrm{g}}$-up and $\mathrm{Mn}^{3+} 3 \mathrm{dt}_{2 \mathrm{~g}}$-down orbitals. However, the $\mathrm{Mn}^{3+} 3 \mathrm{dt}_{2 \mathrm{~g}}$-down orbital contributes little to this energy position from the $\mathrm{O} \mathrm{K}$-edge in Figure $4 \mathrm{a}$. Therefore, the main source of partial covalency is $\mathrm{Co}^{3+} 3 \mathrm{~d} \mathrm{e}_{\mathrm{g}}$-up orbital for P2. Similarly, since $\mathrm{Co}^{3+} 3 \mathrm{~d} \mathrm{e}_{\mathrm{g}}$-down orbital contributes little to the P3 energy position, the main source of partial covalency is the $\mathrm{Mn}^{4+} 3 \mathrm{~d} \mathrm{e}_{\mathrm{g}}$-down orbital for P3. Finally, the relationship between the four Gaussian features and main partial covalency is concluded in Table 1. 

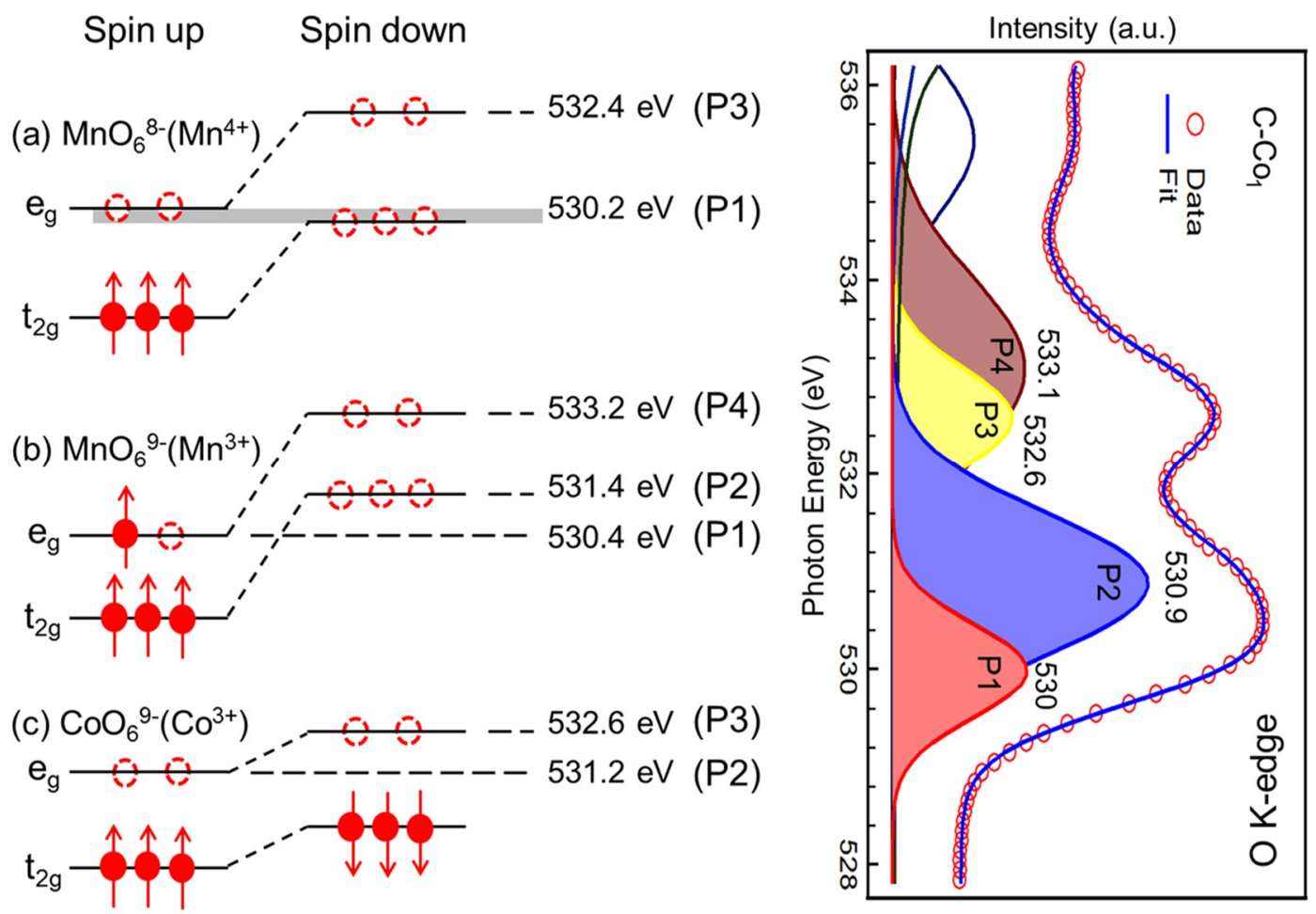

Figure 5. The correlation between four Gaussian peaks of pre-edge portion and partial covalency of specific 3d orbitals. (Left) Experimental molecular orbital diagrams based on the XAS spectra. The three clusters, (a) $\mathrm{MnO}_{6}{ }^{8-}$, (b) $\mathrm{MnO}_{6}{ }^{9-}$, and (c) $\mathrm{CoO}_{6}{ }^{9-}$ correspond to $\mathrm{Mn}^{4+}, \mathrm{Mn}^{3+}$, and $\mathrm{Co}^{3+}$ in octahedral structure, respectively. (Right) O-K pre-edge XAS signals with peak decomposition of $\mathrm{C}-\mathrm{Co}_{1}$.

Table 1. The correspondence between the Gaussian peak and partial covalency.

\begin{tabular}{cc}
\hline Gaussian Peak (Energy Position) & Main Partial Covalency \\
\hline P1 $(\sim 530.0 \mathrm{eV})$ & $\mathrm{Mn}^{4+} 3 \mathrm{~d} \mathrm{t}_{2 \mathrm{~g}}$-down and e $e_{\mathrm{g}}$-up orbital, $\mathrm{Mn}^{3+} 3 \mathrm{~d}$ e $\mathrm{g}$-up orbital \\
P2 $(\sim 530.9 \mathrm{eV})$ & $\mathrm{Co}^{3+} 3 \mathrm{~d} \mathrm{e}_{\mathrm{g}}$-up orbital \\
P3 $(\sim 532.6 \mathrm{eV})$ & $\mathrm{Mn}^{4+} 3 \mathrm{~d} \mathrm{e}_{\mathrm{g}}$-down orbital \\
P4 $(\sim 533.1 \mathrm{e} \mathrm{V})$ & $\mathrm{Mn}^{3+} 3 \mathrm{~d} \mathrm{e}_{\mathrm{g}}$-down orbital \\
\hline
\end{tabular}

After distinguishing the partial covalency, its relationship with the ORR activity is analyzed. Since the valence of the metals has little change, the area of the Gaussian feature is mainly determined by the metal ratio and the covalent strength. We normalize the Gaussian feature area to the metal ratio to represent the covalent strength. The relationship between the strength of partial covalency with the half-wave potential $E_{1 / 2}$ for the cubic and tetragonal spinel oxides shows in Figure 6a,b, respectively. For both cubic and tetragonal phase, increasing the covalent strength of P1 and P2 positively affects ORR activity, while increasing the covalent strength of P3 and P4 negatively affects ORR activity in tetragonal and cubic phase, respectively. This illustrates that the partial covalency of P1 and P2 can boost the ORR catalytic activities, while the partial covalency of P3 and P4 may demote the ORR catalytic activities. As displayed in Table 1, the main origin of the partial covalency of $\mathrm{P} 1 \mathrm{is} \mathrm{Mn}^{4+}$ $3 \mathrm{~d}_{2 \mathrm{~g}}$-down/ $\mathrm{e}_{\mathrm{g}}$-up and $\mathrm{Mn}^{3+} 3 \mathrm{~d} \mathrm{e}_{\mathrm{g}}$-up orbitals, and P2 is $\mathrm{Co}^{3+} 3 \mathrm{~d} \mathrm{e}_{\mathrm{g}}$-up orbital. That is to say, the enhanced ORR catalytic activities can be attributed to the raised partial covalent strength of $\mathrm{O} 2 \mathrm{p}$ orbital with $\mathrm{Mn}^{4+} 3 \mathrm{~d} \mathrm{t}_{2 \mathrm{~g}}$-down/ $\mathrm{e}_{\mathrm{g}}$-up, $\mathrm{Mn}^{3+} 3 \mathrm{~d} \mathrm{e}_{\mathrm{g}}$-up, and $\mathrm{Co}^{3+} 3 \mathrm{~d} \mathrm{e}_{\mathrm{g}}$-up orbitals in this spinel system. 

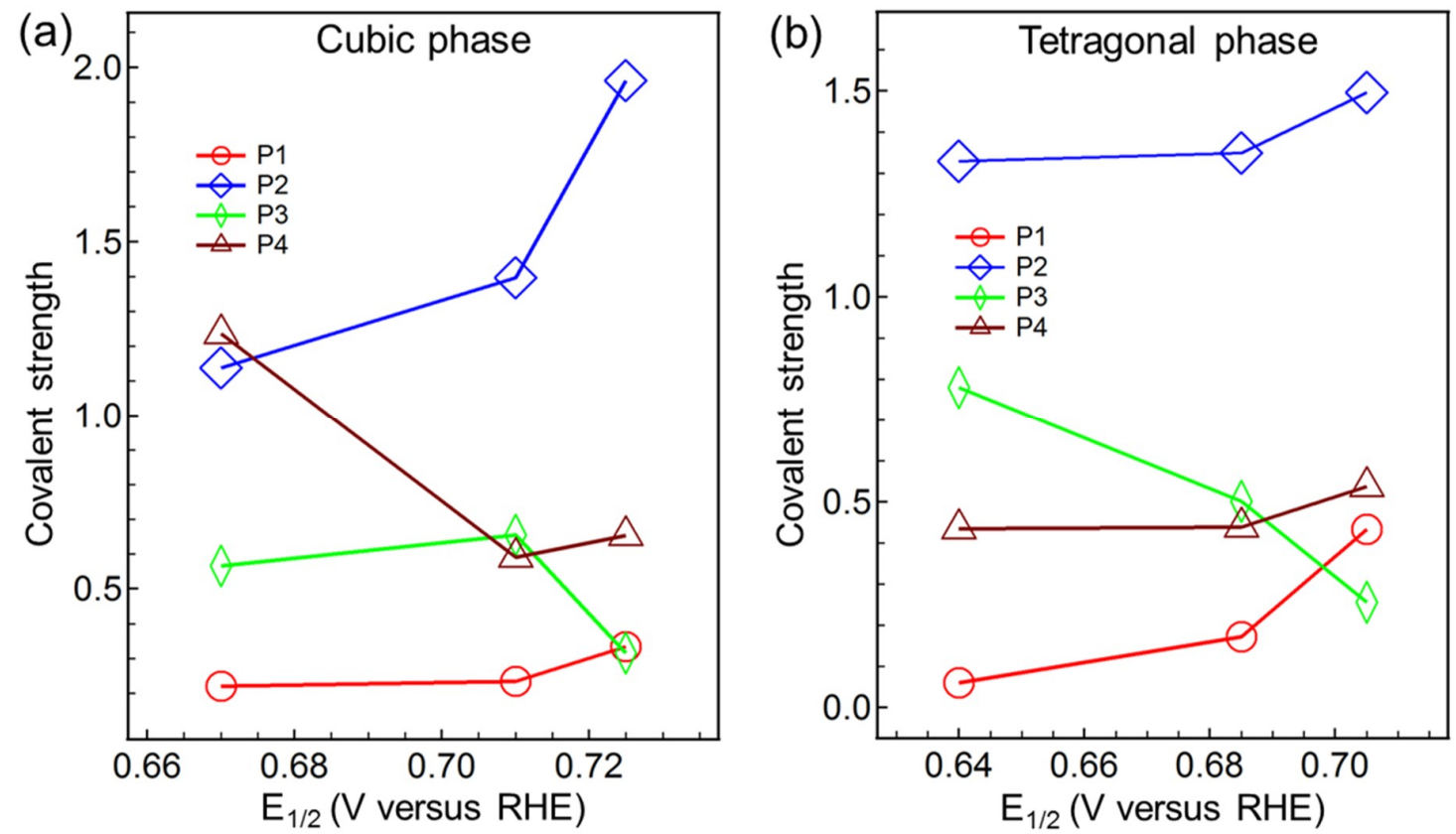

Figure 6. The relationship between the partial $\mathrm{M} 3 \mathrm{~d}-\mathrm{O} 2 \mathrm{p}$ covalency strength and ORR catalytic activities. The covalency strength of P1, P2, P3, and P4 versus the half-wave potential $\mathrm{E}_{1 / 2}$ in the cubic (a) and tetragonal (b) phase.

Previous researches have demonstrated that the stronger covalent strength of M 3d-O 2p, the more ORR electrocatalytic activity of the oxide can be promoted $[19,24]$, where the covalent strength of $\mathrm{M}-\mathrm{O}$ are thought to have a critical impact on the rate of desorption and adsorption steps. Our study indicates that not all the covalency of metal $3 \mathrm{~d}$ orbital and $\mathrm{O} 2 \mathrm{p}$ orbital have a positive push effect on ORR activity. Specifically, the partial covalency of $\mathrm{O} 2 \mathrm{p}$ orbital with $\mathrm{Mn}^{4+} 3 \mathrm{~d} \mathrm{t}_{2 \mathrm{~g}}$-down/ $\mathrm{e}_{\mathrm{g}}$-up, $\mathrm{Mn}^{3+} 3 \mathrm{~d} \mathrm{e}_{\mathrm{g}}$-up, and $\mathrm{Co}^{3+} 3 \mathrm{~d}$ eg-up orbitals is benefit for ORR activity. It is consistent with the common sense that the $\mathrm{e}_{\mathrm{g}}$ orbitals of the metal, rather than the $t_{2 g}$ orbitals, interact more easily with the oxygen orbital to produce an adsorbed intermediate with end-on absorption mode [44,45]. In addition, the single electron in $\mathrm{Mn}^{3+} 3 \mathrm{~d} \mathrm{e}_{\mathrm{g}}$-up orbital is also important for the improving catalytic activity. As discussed in previous reports, the existence of a single $e_{\mathrm{g}}$ electron in the TM ion is able to form a covalent interaction with the adsorbate [46] and the proper number of $e_{g}$ orbital electron filling can well modulate the balance of intermediates displacement in rate-limiting reactions during traditional four-electron ORR proceeds (Figure S2 in Supplementary Materials) [19-22]. On account of the above discussion, variations in the ORR performance between $\mathrm{Co}_{\mathrm{x}} \mathrm{Mn}_{3-\mathrm{x}} \mathrm{O}_{4}(\mathrm{x}=1,1.5,2)$ can be modified by the partial covalency of $\mathrm{TM}$ $3 \mathrm{~d}-\mathrm{O} 2 \mathrm{p}$ by tuning the interaction between spinel catalyst and the molecular oxygen. This may open up a new way to find high-efficiency ORR catalysts by introducing other metals to tune the partial covalent states of M 3d-O 2p.

\section{Conclusions}

In summary, we have studied a substitution strategy to tune the electronic structure of $\mathrm{Co}_{x} \mathrm{Mn}_{3-\mathrm{x}} \mathrm{O}_{4}$ in terms of TM 3d-O 2p covalency, especially the partial covalency between $\mathrm{Mn}^{4+} 3 \mathrm{~d} \mathrm{t}_{2 \mathrm{~g}}$-down/e $\mathrm{e}_{\mathrm{g}}$-up, $\mathrm{Mn}^{3+} 3 \mathrm{~d} \mathrm{e}_{\mathrm{g}}$-up, and $\mathrm{Co}^{3+} 3 \mathrm{~d} \mathrm{e}_{\mathrm{g}}$-up orbitals with $\mathrm{O} 2 \mathrm{p}$ orbital, for enhancing the ORR activity. The ORR performance increases with the increase of Mn content in both cubic and tetragonal phases. The electronic structure of metal (cobalt and manganese) has very little changes for the substitution of Co by $\mathrm{Mn}$, however, the electronic structure of $\mathrm{O}$ can be significantly regulated by studying sXAS. In other words, the factor determining the ORR activity are related to the M 3d-O 2p covalency. More important, the partial covalency between $\mathrm{Mn}^{4+} 3 \mathrm{~d} \mathrm{t}_{2 \mathrm{~g}}$-down $/ \mathrm{e}_{\mathrm{g}}-\mathrm{up}, \mathrm{Mn}^{3+} 3 \mathrm{~d} \mathrm{e}_{\mathrm{g}}$-up, and $\mathrm{Co}^{3+} 3 \mathrm{~d}$ $e_{g}$-up orbitals with $\mathrm{O} 2 \mathrm{p}$ orbital plays an significant role on the ORR catalytic activities by further 
analysis of $\mathrm{O} \mathrm{K}$-edge, such as integration and peak deconvolution. Our findings demonstrate the key role of partial covalency between specific metal $3 \mathrm{~d}$ orbitals and $\mathrm{O} 2 \mathrm{p}$ orbital in enhancing the ORR activity, which can provide a new avenue to designing high efficiency catalyst materials for clean energy conversion and storage devices.

Supplementary Materials: The following are available online at http:/ /www.mdpi.com/2079-4991/9/4/577/ s1. Figure S1: The $\mathrm{O}$ K-edge sXAS signals of the spinel $\mathrm{Co}_{\mathrm{x}} \mathrm{Mn}_{3-\mathrm{x}} \mathrm{O}_{4}$ oxides. After subtracting an arctangent background, eight Gaussian functions were employed to fit the sXAS spectrum. Figure S2: Proposed traditional four-electron ORR mechanism on spinel oxide catalysts. The ORR proceeds via four steps: 1, surface oxygen gas adsorption; 2 , surface peroxide formation; 3 , surface oxide formation; 4 , surface hydroxide regeneration. $M$ is a transition-metal cation in octahedral sites. Table S1: The full width at half maximum (FWHM) of the Gaussian functions and the arctangent background (ATAN function) for the O K-edge sXAS spectra peak deconvolution of the cubic and tetragonal spinel oxides (unit: eV). Table S2: The energy position of the Gaussian functions and ATAN function for the O K-edge sXAS spectra peak deconvolution of the cubic and tetragonal spinel oxides (unit: $\mathrm{eV}$ ).

Author Contributions: Conceptualization, X.L. (Xiaosong Liu); Data curation, X.L. (Xinghui Long), P.Y., N.Z., X.F., G.R., S.Z., and J.F.; Formal analysis, P.Y., N.Z., X.F., and F.C.; Funding acquisition, X.L. (Xiaosong Liu); Investigation, X.L. (Xinghui Long); Methodology, X.L. (Xinghui Long), P.Y., N.Z., and X.F.; Project administration, X.L. (Xiaosong Liu); Resources, C.L. and F.C.; Software, X.L. (Xinghui Long); Supervision, X.L. (Xiaosong Liu); Writing-original draft, X.L. (Xinghui Long), P.Y. and N.Z.; Writing-review \& editing, X.L. (Xiaosong Liu).

Funding: This research was funded by the National Natural Science Foundation of China, grant number 21473235, U1632269, 11227902, and 21503263.

Acknowledgments: The authors thank Jun Chen at Nankai University for fruitful discussion on cubic and tetragonal $\mathrm{Co}_{\mathrm{x}} \mathrm{Mn}_{3-\mathrm{x}} \mathrm{O}_{4}(\mathrm{x}=1,1.5,2)$ synthesis and ORR electrocatalysis experiments. The authors also thank Jenn-Min Lee and Jin-Ming Chen for helpful discussions about sXAS experiment and analysis and synchrotron Taiwan Light Source (TLS) for providing beamtime at the 20A1 beamline.

Conflicts of Interest: The authors declare no conflict of interest.

\section{References}

1. Gray, H.B. Powering the Planet with Solar Fuel. Nat. Chem. 2009, 1, 7. [CrossRef] [PubMed]

2. Dau, H.; Limberg, C.; Reier, T.; Risch, M.; Roggan, S.; Strasser, P. The Mechanism of Water Oxidation: From Electrolysis via Homogeneous to Biological Catalysis. ChemCatChem 2010, 2, 724-761. [CrossRef]

3. Wang, Z.L.; Xu, D.; Xu, J.J.; Zhang, X.B. Oxygen electrocatalysts in metal-air batteries: From aqueous to nonaqueous electrolytes. Chem. Soc. Rev. 2014, 43, 7746-7786. [CrossRef] [PubMed]

4. Service, R.F. Hydrogen Cars: Fad or the Future? Science 2009, 324, 1257-1259. [CrossRef] [PubMed]

5. Chen, C.; Kang, Y.; Huo, Z.; Zhu, Z.; Huang, W.; Xin, H.L.; Snyder, J.D.; Li, D.; Herron, J.A.; Mavrikakis, M.; et al. Highly crystalline multimetallic nanoframes with three-dimensional electrocatalytic surfaces. Science 2014, 343, 1339-1343. [CrossRef]

6. Lee, Y.; Suntivich, J.; May, K.J.; Perry, E.E.; Shao-Horn, Y. Synthesis and Activities of Rutile $\mathrm{IrO}_{2} \mathrm{and} \mathrm{RuO}_{2}$ Nanoparticles for Oxygen Evolution in Acid and Alkaline Solutions. J. Phys. Chem. Lett. 2012, 3, 399-404. [CrossRef]

7. Luo, Z.; Marti-Sanchez, S.; Nafria, R.; Joshua, G.; de la Mata, M.; Guardia, P.; Flox, C.; Martinez-Boubeta, C.; Simeonidis, K.; Llorca, J.; Morante, J.R.; Arbiol, J.; Ibanez, M.; Cabot, A. $\mathrm{Fe}_{3} \mathrm{O}_{4} @ \mathrm{NiFe}_{\mathrm{x}} \mathrm{O}_{\mathrm{y}} \mathrm{Nanoparticles}$ with Enhanced Electrocatalytic Properties for Oxygen Evolution in Carbonate Electrolyte. ACS Appl. Mater. Interfaces 2016, 8, 29461-29469. [CrossRef]

8. Davodi, F.; Tavakkoli, M.; Lahtinen, J.; Kallio, T. Straightforward synthesis of nitrogen-doped carbon nanotubes as highly active bifunctional electrocatalysts for full water splitting. J. Catal. 2017, 353, 19-27. [CrossRef]

9. Davodi, F.; Muhlhausen, E.; Tavakkoli, M.; Sainio, J.; Jiang, H.; Gokce, B.; Marzun, G.; Kallio, T. Catalyst Support Effect on the Activity and Durability of Magnetic Nanoparticles: Toward Design of Advanced Electrocatalyst for Full Water Splitting. ACS Appl. Mater. Interfaces 2018, 10, 31300-31311. [CrossRef]

10. Rios, E.; Gautier, J.-L.; Poillerat, G.; Chartier, P. Mixed Valency Spinel Oxides of Transition Metals and Electrocatalysis: Case of the $\mathrm{Mn}_{\mathrm{x}} \mathrm{Co}_{3-\mathrm{x}} \mathrm{O}_{4}$ System. Electrochim. Acta 1998, 44, 1491-1497. [CrossRef] 
11. Ponce, J.; Rehspringer, J.-L.; Poillerat, G.; Gautier, J.L. Electrochemical study of nickel-aluminium-manganese spinel $\mathrm{Ni}_{\mathrm{x}} \mathrm{Al}_{1-\mathrm{x}} \mathrm{Mn}_{2} \mathrm{O}_{4}$. Electrocatalytical properties for the oxygen evolution reaction and oxygen reduction reaction in alkaline media. Electrochim. Acta 2001, 46, 3373-3380. [CrossRef]

12. Cui, B.; Lin, H.; Li, J.-B.; Li, X.; Yang, J.; Tao, J. Core-Ring Structured $\mathrm{NiCo}_{2} \mathrm{O}_{4}$ Nanoplatelets: Synthesis, Characterization, and Electrocatalytic Applications. Adv. Funct. Mater. 2008, 18, 1440-1447. [CrossRef]

13. Li, Y.; Hasin, P.; $\mathrm{Wu}, \mathrm{Y} . \mathrm{Ni}_{\mathrm{x}} \mathrm{Co}_{3-\mathrm{x}} \mathrm{O}_{4}$ nanowire arrays for electrocatalytic oxygen evolution. Adv. Mater. 2010, 22, 1926-1929. [CrossRef]

14. Wang, H.; Yang, Y.; Liang, Y.; Zheng, G.; Li, Y.; Cui, Y.; Dai, H. Rechargeable Li-O 2 batteries with a covalently coupled $\mathrm{MnCo}_{2} \mathrm{O}_{4}$-graphene hybrid as an oxygen cathode catalyst. Energy Environ. Sci. 2012, 5, 7931. [CrossRef]

15. Zhang, L.; Zhang, S.; Zhang, K.; Xu, G.; He, X.; Dong, S.; Liu, Z.; Huang, C.; Gu, L.; Cui, G. Mesoporous $\mathrm{NiCo}_{2} \mathrm{O}_{4}$ nanoflakes as electrocatalysts for rechargeable $\mathrm{Li}-\mathrm{O}_{2}$ batteries. Chem. Commun. 2013, 49, 3540-3542. [CrossRef] [PubMed]

16. Kim, T.W.; Woo, M.A.; Regis, M.; Choi, K.-S. Electrochemical Synthesis of Spinel Type $\mathrm{ZnCo}_{2} \mathrm{O}_{4}$ Electrodes for Use as Oxygen Evolution Reaction Catalysts. J. Phys. Chem. Lett. 2014, 5, 2370-2374. [CrossRef] [PubMed]

17. Rios, E.; Chartier, P.; Gautier, J.-L. Oxygen Evolution Electrocatalysis in Alkaline Medium at thin $\mathrm{Mn}_{\mathrm{x}} \mathrm{Co}_{3-\mathrm{x}} \mathrm{O}_{4}$ $(0<x<1)$ Spinel Films on Glass $/ \mathrm{SnO}_{2}$ : F Prepared by Spray Pyrolysis. Solid State Sci. 1999, 1, 267-277.

18. Restovic, A.; Rı'os, E.; Barbato, S.; Ortiz, J.; Gautier, J.L. Oxygen Reduction in Alkaline Medium at Thin $\mathrm{Mn}_{\mathrm{x}} \mathrm{Co}_{3-\mathrm{x}} \mathrm{O}_{4}(0<\mathrm{x}<1)$ Spinel Films Prepared by Spray Pyrolysis. Effect of Oxide Cation Composition on the Reaction Kinetics. J. Electroanal. Chem. 2002, 522, 141-151.

19. Suntivich, J.; Gasteiger, H.A.; Yabuuchi, N.; Nakanishi, H.; Goodenough, J.B.; Shao-Horn, Y. Design principles for oxygen-reduction activity on perovskite oxide catalysts for fuel cells and metal-air batteries. Nat. Chem. 2011, 3, 546-550. [CrossRef]

20. Suntivich, J.; May, K.J.; Gasteiger, H.A.; Goodenough, J.B.; Shao-Horn, Y. A perovskite oxide optimized for oxygen evolution catalysis from molecular orbital principles. Science 2011, 334, 1383-1385. [CrossRef] [PubMed]

21. Wei, C.; Feng, Z.; Scherer, G.G.; Barber, J.; Shao-Horn, Y.; Xu, Z.J. Cations in Octahedral Sites: A Descriptor for Oxygen Electrocatalysis on Transition-Metal Spinels. Adv. Mater. 2017, 29, 1606800. [CrossRef]

22. Zhou, Y.; Sun, S.; Xi, S.; Duan, Y.; Sritharan, T.; Du, Y.; Xu, Z.J. Superexchange Effects on Oxygen Reduction Activity of Edge-Sharing [Cox $\mathrm{Mn}_{1-\mathrm{x}} \mathrm{O}_{6}$ ] Octahedra in Spinel Oxide. Adv. Mater. 2018, 30, 1705407. [CrossRef] [PubMed]

23. Mueller, D.N.; Machala, M.L.; Bluhm, H.; Chueh, W.C. Redox activity of surface oxygen anions in oxygen-deficient perovskite oxides during electrochemical reactions. Nat. Commun. 2015, 6, 6097. [CrossRef] [PubMed]

24. Suntivich, J.; Hong, W.T.; Lee, Y.-L.; Rondinelli, J.M.; Yang, W.; Goodenough, J.B.; Dabrowski, B.; Freeland, J.W.; Shao-Horn, Y. Estimating Hybridization of Transition Metal and Oxygen States in Perovskites from O K-edge X-ray Absorption Spectroscopy. J. Phys. Chem. C 2014, 118, 1856-1863. [CrossRef]

25. Cheng, F.; Shen, J.; Peng, B.; Pan, Y.; Tao, Z.; Chen, J. Rapid room-temperature synthesis of nanocrystalline spinels as oxygen reduction and evolution electrocatalysts. Nat. Chem. 2011, 3, 79-84. [CrossRef] [PubMed]

26. Li, C.; Han, X.; Cheng, F.; Hu, Y.; Chen, C.; Chen, J. Phase and composition controllable synthesis of cobalt manganese spinel nanoparticles towards efficient oxygen electrocatalysis. Nat. Commun. 2015, 6, 7345. [CrossRef] [PubMed]

27. Chung, S.C.; Chen, C.I.; Tseng, P.C.; Lin, H.F.; Dann, T.E.; Song, Y.F.; Huang, L.R.; Chen, C.C.; Chuang, J.M.; Tsang, K.L.; et al. Soft X-ray spectroscopy beamline $6 \mathrm{~m}$ high energy spherical grating monochromator at SRRC: Optical design and first performance tests. Rev. Sci. Instrum. 1995, 66, 1655-1657. [CrossRef]

28. Morales, F.; de Groot, F.M.F.; Glatzel, P.; Kleimenov, E.; Bluhm, H.; Havecker, M.; Knop-Gericke, A.; Weckhuysen, B.M. In Situ X-ray Absorption of $\mathrm{Co} / \mathrm{Mn} / \mathrm{TiO}_{2}$ Catalysts for Fischer-Tropsch Synthesis. J. Phys. Chem. B 2004, 108, 16201-16207. [CrossRef]

29. Ghiasi, M.; Delgado-Jaime, M.U.; Malekzadeh, A.; Wang, R.-P.; Miedema, P.S.; Beye, M.; de Groot, F.M.F. Mn and Co Charge and Spin Evolutions in $\mathrm{LaMn}_{1-\mathrm{x}} \mathrm{Co}_{x} \mathrm{O}_{3}$ Nanoparticles. J. Phys. Chem. C 2016, 120, 8167-8174. [CrossRef] 
30. Lin, F.; Markus, I.M.; Nordlund, D.; Weng, T.C.; Asta, M.D.; Xin, H.L.; Doeff, M.M. Surface reconstruction and chemical evolution of stoichiometric layered cathode materials for lithium-ion batteries. Nat. Commun. 2014, 5, 3529. [CrossRef] [PubMed]

31. Chang, C.F.; Hu, Z.; Wu, H.; Burnus, T.; Hollmann, N.; Benomar, M.; Lorenz, T.; Tanaka, A.; Lin, H.J.; Hsieh, H.H.; et al. Spin Blockade, Orbital Occupation, and Charge Ordering in $\mathrm{La}_{1.5} \mathrm{Sr}_{0.5} \mathrm{CoO}_{4}$. Phys. Rev. Lett. 2009, 102, 116401. [CrossRef] [PubMed]

32. Suchow, L. A Detailed, Simple Crystal Field Consideration of the Normal Spinel Structure of $\mathrm{Co}_{3} \mathrm{O}_{4}$. J. Chem. Educ. 1976, 53, 560. [CrossRef]

33. Kim, K.J.; Park, Y.R. Optical investigation of charge-transfer transitions in spinel $\mathrm{Co}_{3} \mathrm{O}_{4}$. Solid State Commun. 2003, 127, 25-28. [CrossRef]

34. Liang, Y.; Wang, H.; Zhou, J.; Li, Y.; Wang, J.; Regier, T.; Dai, H. Covalent hybrid of spinel manganese-cobalt oxide and graphene as advanced oxygen reduction electrocatalysts. J. Am. Chem. Soc. 2012, 134, 3517-3523. [CrossRef] [PubMed]

35. Qiao, R.; Wang, Y.; Olalde-Velasco, P.; Li, H.; Hu, Y.-S.; Yang, W. Direct evidence of gradient Mn(II) evolution at charged states in $\mathrm{LiNi}_{0.5} \mathrm{Mn}_{1.5} \mathrm{O}_{4}$ electrodes with capacity fading. J. Power Sources 2015, 273, 1120-1126. [CrossRef]

36. Qiao, R.; Chin, T.; Harris, S.J.; Yan, S.; Yang, W. Spectroscopic fingerprints of valence and spin states in manganese oxides and fluorides. Curr. Appl. Phys. 2013, 13, 544-548. [CrossRef]

37. Cramer, S.P.; DeGroot, F.M.F.; Ma, Y.; Chen, C.T.; Sette, F.; Kipke, C.A.; Eichhorn, D.M.; Chan, M.K.; Armstrong, W.H. Ligand Field Strengths and Oxidation States From Manganese L-Edge Spectroscopy. J. Am. Chem. Soc. 1991, 113, 7937-7940. [CrossRef]

38. Thole, B.T.; Vanderlaan, G. Branching Ratio in X-ray Absorption Spectroscopy. Phys. Rev. B 1988, 38, 3158-3171. [CrossRef]

39. Ralston, C.Y.; Wang, H.; Ragsdale, S.W.; Kumar, M.; Spangler, N.J.; Ludden, P.W.; Gu, W.; Jones, R.M.; Patil, D.S.; Cramer, S.P. Characterization of Heterogeneous Nickel Sites in CO Dehydrogenases from Clostridium thermoaceticum and Rhodospirillum rubrum by Nickel L-Edge X-ray Spectroscopy. J. Am. Chem. Soc. 2000, 122, 10553-10560. [CrossRef]

40. Kurata, H.; Colliex, C. Electron-energy-loss core-edge structures in manganese oxides. Phys. Rev. B 1993, 48, 2102-2108. [CrossRef]

41. De Groot, F.M.F.; Grioni, M.; Fuggle, J.C.; Ghijsen, J.; Sawatzky, G.A.; Petersen, H. Oxygen 1s X-ray-Absorption Edges of Transition-Metal Oxides. Phys. Rev. B 1989, 40, 5715-5723. [CrossRef]

42. Minasian, S.G.; Keith, J.M.; Batista, E.R.; Boland, K.S.; Bradley, J.A.; Daly, S.R.; Kozimor, S.A.; Lukens, W.W.; Martin, R.L.; Nordlund, D.; et al. Covalency in metal-oxygen multiple bonds evaluated using oxygen K-edge spectroscopy and electronic structure theory. J. Am. Chem. Soc. 2013, 135, 1864-1871. [CrossRef] [PubMed]

43. Ye, Y.; Thorne, J.E.; Wu, C.H.; Liu, Y.S.; Du, C.; Jang, J.W.; Liu, E.; Wang, D.; Guo, J. Strong O 2p-Fe 3d Hybridization Observed in Solution-Grown Hematite Films by Soft X-ray Spectroscopies. J. Phys. Chem. B 2018, 122, 927-932. [CrossRef] [PubMed]

44. Matsumoto, Y.; Yoneyama, H.; Tamura, H. Influence of the Nature of the Conduction Band of Transition Metal Oxides on Catalytic Activity for Oxygen Reduction. J. Electroanal. Chem. 1977, 83, 237-243. [CrossRef]

45. Yeager, E. Dioxygen Electrocatalysis: Mechanisms in Relation to Catalyst Structure. J. Mol. Catal. 1986, 38, 5-25. [CrossRef]

46. Ahmad, E.A.; Tileli, V.; Kramer, D.; Mallia, G.; Stoerzinger, K.A.; Shao-Horn, Y.; Kucernak, A.R.; Harrison, N.M. Optimizing Oxygen Reduction Catalyst Morphologies from First Principles. J. Phys. Chem. C 2015, 119, 16804-16810. [CrossRef]

(C) 2019 by the authors. Licensee MDPI, Basel, Switzerland. This article is an open access article distributed under the terms and conditions of the Creative Commons Attribution (CC BY) license (http://creativecommons.org/licenses/by/4.0/). 